\title{
Sınıf Öğretmeni Adaylarının Teknolojik Pedagojik Alan Bilgilerinin (TPAB) Bazı Değişkenlere Göre İncelenmesi
}

\section{Examining Technological Pedagogical and Content Knowledge (TPACK) Levels of Primary Pre-Service Teachers Based on Some Variables}

\author{
Salih AKYILDIZ ${ }^{1}$, Taner ALTUN ${ }^{2}$
}

\begin{abstract}
Öz: $\mathrm{Bu}$ araştırmanın amacı sınıf öğretmenliği programında öğrenim gören son sınıf öğretmen adaylarının Teknolojik Pedagojik Alan Bilgisi (TPAB) düzeylerinin bazı değişkenlere göre incelemektir. Nicel yaklaşım çerçevesinde tasarlanan çalışmada tarama yöntemi kullanılmıştır. Araştırma, 2015-2016 eğitim-öğretim yılının bahar yarıyılında Karadeniz Teknik Fatih Eğitim Fakültesi Sınıf Öğretmenliği Anabilim Dalında öğrenim gören 329 öğretmen adayının katılımıyla gerçekleştirilmiştir. Araştırmada, veri toplama aracı olarak Schmidt ve diğerleri (2009) tarafindan geliştirilen ve Türkçeye uyarlanması Bahçekapılı, (2011) tarafindan yapılan Öğretmen Adayları Teknolojik Pedagojik Alan Bilgisi ölçeği kullanılmıştır. Araştırmada elde edilen veriler SPSS 18.0 yazılım programı kullanılarak analiz edilmiştir. Araştırma sonuçlarına göre sınıf öğretmeni adaylarının genel Teknolojik Pedagojik Alan Bilgiler "iyi” düzeydedir. Cinsiyet değişkeni açısından kadın öğretmen adaylarının, pedagoji bilgisi, pedagojik alan bilgisi, teknolojik pedagoji bilgisi ve teknolojik pedagojik alan bilgisi boyutlarında erkek öğretmen adaylarına göre daha iyi düzeyde oldukları belirlenmiştir. Kişisel bilgisayara ve internet erişimine sahip olma değişkenleri açısından da ölçeğin alt boyutlarının bazılarında anlamlı farklılıklar tespit edilmiştir. Araştırmanın sonunda sınıf öğretmeni yetiştiren kurumlara yönelik çeşitli öneriler sunulmuştur.
\end{abstract}

Anahtar sözcükler: Sinıf ögretmeni adayları, Teknolojik Pedagojik Alan Bilgisi, cinsiyet.

\begin{abstract}
The purpose of this study is to examine Technological Pedagogical and Content Knowledge (TPACK) levels of primary pre-service teachers based on different variables. Study was designed within the quantitative research approach and survey method was utilized. The study was with 329 primary-preservice education teachers who attend Primary Teacher Education Programme at Karadeniz Technical University in 2015-2016 academic year. Survey of Preservice Teachers' Knowledge of Teaching and Technology scale which was developed by Schmidt et al (2009) and adopted to Turkish by Bahcekapili (2011) was used as the main data collection instrument. Obtained data were analyzed utilizing the SPSS 18.0 software. Results of the study illustrate that participant teachers have "good" level of TPACK in general. It was determined that female pre-service teachers are better than male counterparts in pedagogical knowledge, pedagogical content knowledge, and technological pedagogical content knowledge dimensions of the scale. Meaningful
\end{abstract}

\footnotetext{
${ }^{1}$ Yrd. Doç. Dr., Karadeniz Teknik Üniversitesi, e-posta: sakyildiz61@gmail.com

${ }^{2}$ Doç. Dr., Karadeniz Teknik Üniversitesi, e-posta: taltun@ktu.edu.tr
} 
differences were also found at sub-dimensions of the scale based on having personal computer and internet access variables. At the end of the study some recommendations were presented for teacher education institutions.

Keywords: Primary pre-service teachers, gender, Technological Pedagogical and Content Knowledge.

\section{GíRiş}

Daha önceleri öğretmenlik mesleği standartlarındaki anlayış davranışçı yaklaşımlara dayandırılırken, günümüzde bu anlayışın yerini alan bilgisi, pedagojinin ve teknolojinin bütünleştirildiği teknolojik pedagojik alan bilgisi anlayışına dönüştürüldüğü görülmektedir (TED, 2009; 174). Bu durum öğretmenlerin teknolojiyi öğretme-öğrenme sürecinde etkin bir biçimde entegre etmeleri gerektiğini ortaya koymaktadır. Ancak teknolojinin öğretimde kullanılabilmesi için öğretmenlerin teknoloji, pedagoji ve alan bilgilerine sahip olmaları gerekmektedir (Koehler ve Mishra, 2005; 2008).

Shulman (1986) tarafindan kullanılan pedagojik alan bilgisi kavramına daha sonra teknoloji bilgisi eklenerek kavram genişlemiş ve Teknolojik Pedagojik Alan Bilgisi (TPAB) olarak kullanılmaya başlamıştır. TPAB modeli teknoloji, pedagoji ve alan (içerik) bileşeninden oluşmaktadır. Teknoloji bileşeni, bilgisayar, internet, video, tahta, kitap gibi araçları; pedagoji bileşeni, öğrenme ve öğretme yöntemlerini, stratejileri, süreçleri; içerik bileşeni ise öğrenilecek olan konu alanı bilgisini kapsamaktadır (Kuşkaya-Mumcu, Haşlaman ve Usluel, 2008:397). TPAB'ın kavramsallaşmasında, Koehler ve Mishra'nın çalışmaları önemli rol oynamıştır. Koehler ve Mishra (2005; 2008; 2009), TPAB'ın etkileşimde olduğu bileşenleri gösteren bir model ortaya koymuştur.

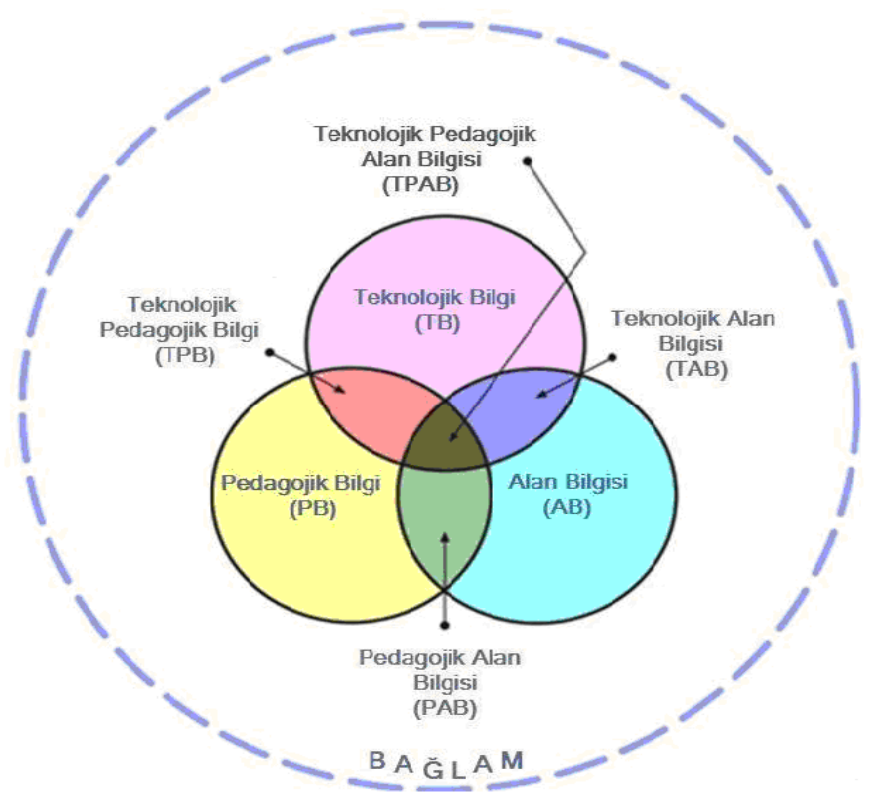

Şekil 1. TPAB ve etkileşimli olduğu bilgi türleri. 
Şekil 1'de görüldüğü gibi, Teknolojik Pedagojik Alan Bilgisi'nin temelinde Teknoloji bilgisi (TB), Pedagoji bilgisi (PB) ve Alan bilgisi (AB) yer almaktadır. Bu üç bilgi türünün birbirleriyle kesiştiği yerlerde de Teknolojik alan bilgisi (TAB), Pedagojik alan bilgisi (PAB) ve Teknolojik pedagojik bilgisi(TPB) ortaya çıkmıştır. TPAB ise tüm bu bilgi türlerinin birbirleriyle kesiştiği orta yerde yer almıştır.

Pedagojik alan bilgisi (PAB), hem alan bilgisi hem de pedagojik bilginin birleşiminden oluşmaktadır (Ekiz, 2006). Bu bilgi türü konuyu öğrencinin bireysel özelliklerine, ilgi ve ihtiyaçlarına ve seviyesini göz önüne alarak öğretme bilgisidir (Atay, 2003). Teknolojik pedagojik bilgisi(TPB), öğrenme sürecinde kullanılan teknolojilerin öğretme ve öğrenmenin nasıl değişeceği üzerinde durmaktadır. Seçilen teknolojik araç ve yöntemlerin öğrenme sürecine yapacağı katkıları veya getireceği sınırlılıkları pedagojik yaklaşımlarla birlikte değerlendirme ve teknolojiyi buna göre kullanmayı kapsamaktadır. Teknolojik Pedagojik Alan Bilgisi (TPAB) ise, "öğretim programları ve konu alanı, programın nasıl öğretileceği ve alanın diğer alanlarla ilişkisi, alandaki son gelişmeler, alanın temel kavram, araç ve yapıları, öğretilecek içeriğin teknoloji ile bütünleştirilmesi hakkında bilgili olma” (TED, 2009: XX) alanlarını içermektedir.

Günümüzde, bilgi iletişim teknolojilerinden yararlanmadan öğretim programlarının ekili bir şekilde uygulamaya taşımak pek mümkün değildir. Bu nedenle, gelişen teknolojilerin öğretme-öğrenme sürecine daha etkin kullanımını artırmak amacıyla, eğitim fakültelerinde genel kültür ve pedagoji derslerinde teknolojinin kullanımını sağlamaya yönelik çalışmalar yapılmaktadır. Türkiye'de bu çalışmalar bazı araştırmacılar tarafından "teknopedagoji" olarak ifade edilmiştir (Çoklar, Kılıçer ve Odabaşı, 2007; Gönen ve Kocakaya, 2015; Öksüz, Ak ve Uça, 2009; Şimşek, Demir, Bağçeci ve Kinay, 2013; Yurdakul, 2011). Öğretmen yetiştirme programlarında, teknoloji becerileri kazandırmaya yönelik derslerin yer almasına rağmen, öğretmen adaylarının, eğitim teknolojilerini öğretimin strateji, yöntem-teknik ve ölçme-değerlendirme gibi süreçlerine tam olarak uygulayabilecek niteliği yeterince kazanamadıkları ifade edilmektedir (Altun, 2007; Bilgin, Tatar ve Ay, 2012; Çoklar, Kılıçer ve Odabaşı, 2007).

Diğer yandan, TPAB'ın öğretmenlik mesleğinin yeterlik alanları arasına girmesi ile birlikte bu alanda yapılan araştırmalar da hız kazanmıştır. Yapılan araştırmalar incelendiğinde sınıf öğretmenliği alanında yapılan çalışmaların diğer alanlara göre azlığı dikkat çekmektedir. Örneğin, Sancar-Tokmak ve Yavuz Konakman ve Yanpar Yelken'in (2013) sınıf öğretmeni adaylarının TPAB'larına ilişkin algılarını çeşitli değişkenlere göre inceledikleri çalışmada, "teknolojiye erişim düzeyi, yeni teknolojilere ilgi düzeyi ve teknolojiyi kullanma düzeyi yüksek olan öğretmen adaylarının diğerlerine göre TPAB düzeylerinin daha yüksek olduğunu düşündükleri” saptanmışlardır. Öztürk (2013), sınıf öğretmeni adaylarının TPAB'larına bazı değişkenlere göre değerlendirdikleri çalışmada, TPAB'ın alt boyutlarına göre anlamlı bir farklılık yokken, teknoloji kullanımında kendilerini yeterli hissedip hissetmemeleri değişkenine göre, TPAB'ın alt boyutlarında anlamlı bir farklılık saptanmıştır. Karadeniz ve Vatanartıran'ın (2015), sınıf öğretmenlerinin TPAB'larını inceledikleri çalışmada, sınıf öğretmenlerinin TPAB çerçevesinde kendilerini yeterli buldukları, erkek öğretmenlerin teknoloji bilgisi algılarının kadın öğretmenlere göre daha yüksek olduğunu belirlemişlerdir. Diğer yandan, alan bilgisi ve pedagojik alan bilgisi faktörlerinde, yüksek kıdemi olan öğretmenler düşük kıdemi 
olan öğretmenlere göre kendilerini daha yeterli buldukları bulgusuna ulaşmışlardır. Alanyazında sınıf öğretmenleri ile ilgili benzer çalışmalara ulaşmak mümkündür (Bilgin, Tatar ve Ay, 2012; Bozkurt ve Cilavdaroğlu, 2011; Karakuyu, 2015; Kula, 2015).

Yılmaz (2015), meta analiz çalışmasında, incelediği çalışmaların önemli bir bölümünün "TPAB yeterliklerinin belirlenmesi”, "TPAB ve farklı değişkenler arasındaki ilișkinin incelenmesi”, “TPAB ölçeğinin Türkçe’ye uyarlanıp geçerlilik ve güvenilirliğinin test edilmesi" ve "TPAB gelişiminin incelenmesi” amacryla yapıldığı; diğer amaçlarla yapılan çalışmaların ise sınırlı sayıda olduğuna dikkat çekmektedir. Benzer bir çalışmada Baran ve Bilici (2015), Ocak 2005-Aralık 2013 arasında Türkiye'de yapılmış 30 araştırma incelemişler ve bu araştırmalardan hareketle, ТРАВ alanyazınında fen ve matematik disiplinlerinin ağırlıklı olduğu bulgusuna ulaşmışlardır.

Son yıllarda Milli Eğitim Bakanlığı tarafından yapılan yatırım ve çabalara rağmen eğitim teknolojilerinin öğretme-öğrenme sürecine tam olarak entegre edilemediğgi bilinmektedir. Yukarıdaki açıklamalarda da vurgulandığı gibi, "bir öğretmenin teknolojiyi derslerine entegre edebilmesi için öncelikle TPAB'a sahip olması" gerekmektedir (Yılmaz, 2005: 105). TPAB'ın teknolojinin öğrenme sureciyle bütünleştirilme sürecinde oynadığı rol göz önüne alındığında öğretmen adaylarına hizmet öncesi eğitimlerinde TPAB'1 kazandırmaya uygulamalara daha çok yer verilmesi önem taşımaktadır. Sınıf öğretmenliğinin disiplinler arası bir alan olması teknolojinin bu alana entegrasyonunu kolaylaştırabilir. Ancak, TPAB'ın kavramsal yapısının daha iyi anlaşılabilmesi ve alana daha iyi entegre edilebilmesi için sınıf öğretmenliği alanında daha çok araştırma yapılmasına ihtiyaç vardır.

$\mathrm{Bu}$ araştırmada, sınıf öğretmeni adaylarının TPAB'larının, bu TPAB'lar arasındaki ilişkilerin belirlenmesi ve TPAB'ların cinsiyet, kişisel bilgisayara sahip olma ve internet kullanımı, durumlarına göre farklılaşıp farklılaşmadığının belirlenmesi amaçlanmıştır. Bu amaçla aşağıdaki sorulara yanıt aranmıştır:

1. Sınıf öğretmeni adaylarının genel teknolojik pedagojik alan bilgileri ne düzeydedir?

2. Sınıf öğretmeni adaylarının teknolojik pedagojik alan bilgileri, cinsiyet, değişkenine göre farklılık göstermekte midir?

3. Sınıf öğretmeni adaylarının teknolojik pedagojik alan bilgileri, kişisel bir bilgisayara sahip olma durumuna göre farklılık göstermekte midir?

4. Sınıf öğretmeni adaylarının teknolojik pedagojik alan bilgileri, internete sahip olma durumuna göre farklılık göstermekte midir?

\section{YÖNTEM}

\subsection{Araştırma Modeli}

$\mathrm{Bu}$ araştırma tarama modeline dayalı olarak yürütülmüştür. "Tarama modelleri geçmişte ya da halen var olan bir durumu olduğu gibi betimlemeyi amaçlayan araştırma yaklaşımıdır" (Karasar, 2005). Katılımın geniş olduğu durumlarda tarama yöntemi ideal yöntemlerden biri olarak kabul edilmektedir (Cohen 
ve Manion, 2007). Tarama yöntemlerinde mevcut bir olgu, olay veya durumun olduğu gibi ortaya konması ve betimlenmesi amaçlanmaktadır. Özellikle betimsel tarama araştırmalarında bir grubun belirli konulardaki bazı özelliklerini (örn. görüşlerini, inançlarını, tutumlarını ve/veya bilgilerini) tanımlamaya yönelik veri toplanması amaçlanır (Fraenkel ve Wallen, 2008:390). Bu araştırmada da sınıf öğretmeni adaylarının TPAB düzeylerinin belirlenmesi amacıyla geniş katılımlı örneklem üzerinde bir tarama çalışması yapılmıştır.

\section{2. Çalışma Grubu}

$\mathrm{Bu}$ araştırmanın çalışma grubu, amaçlı örnekleme yöntemi ile seçilmiştir."Bu yöntem yakın ve ulaşılması kolay bir durum seçildiği için araştırmaya hız ve pratiklik kazandırır" (Yıldırım ve Şimşek, 2011). Araştırmanın çalışma grubunu Karadeniz Teknik Üniversitesi, Sınıf Öğretmenliği son sınıfında öğrenim görmekte olan öğretmen adayları oluşturmuştur. Araştırmaya katılanların sınıf öğretmeni adaylarının demografik özellikleri Tablo 1'de yer almıştır.

Tablo 1. Araştırmaya Katılan Sınıf Öğretmeni Adaylarının Demografik Özellikleri

\begin{tabular}{llll}
\hline \multirow{2}{*}{ Ozzellikler } & Özelliklerin Kategorileri & N & \% \\
\hline \multirow{2}{*}{ Cinsiyet } & Kadın & 227 & 69 \\
& Erkek & 102 & 31 \\
\hline \multirow{2}{*}{ Kişisel Bilgisayar } & Var & 286 & 86,9 \\
& Yok & 43 & 13,1 \\
\hline \multirow{2}{*}{ İnternet Bağlantısı } & Var & 264 & 80,2 \\
& Yok & 65 & 19,8 \\
\hline \multirow{2}{*}{ TOPLAM } & & 329 & 100,0 \\
\hline
\end{tabular}

\subsection{Veri Toplama Aracı}

Araştırma verilerinin toplanmasında, Schmidt ve diğerleri (2009) tarafından TPAB'a yönelik geliştirilen ölçme aracı (Survey of Pre-service Teachers' Knowledge of Teaching and Technology) ve Türkçeye uyarlanması Bahçekapılı, (2011) tarafından yapılan ölçme aracı kullanılmıştır. 5'li likert tipi derecelendirmeye sahip ölçme aracında TPAB'ı ölçme amacıyla 47 soru bulunmaktadır. Türkçeye çevrilen ölçek, Karadeniz Teknik Üniversitesi ve Rize Üniversitesi Eğitim Fakültesi sınıf öğretmenliği programlarında öğrenim gören 223 öğrenciden toplanan veriler üzerinden doğrulayıcı faktör analizi uygulanmıştır. Yapılan doğrulayıcı faktör analizi sonucunda, ölçme aracının, belirtilen tüm alt boyutlarda uyum verdiği görülmüştür. DFA'ya yönelik çalışılan örneklemin büyüklüğünden dolayı, $x^{2}$ değeri 1879,901 hesaplanmış ve df ile düzeltilmiş $x^{2}$ değeri dikkate alınmış, $x^{2} /$ sd değeri 1,9 olarak bulunmuştur. Diğer bazı uyum indeksi değerleri; $\mathrm{CFI}=.86, \mathrm{TLI}=.85, \mathrm{RMSEA}=.064$, $\mathrm{SRMR}=.064$ olarak bulunmuştur. Ölçeğin alt boyutları güvenirlik katsayıları Croanbach Alfa değerinin. 80 ile.90 arasında değiştiği görülmektedir. Ölçek, "kesinlikle katılıyorum (5)", "katılıyorum (4)", "kararsızım (3)", "katılmıyorum (2)" ve "hiç katılmıyorum (1)" seklinde beşli derecelendirmeye sahiptir.

\subsection{Verilerin Analizi}


Araştırma verilerinin analizinde SPSS 18.0 paket program kullanılmıştır. Öğretmenlerin görüşleri aritmetik ortalama ve standart sapma teknikleri ile analiz edilmiştir. Öğretmenlerin görüşleri "cinsiyet", “internet" ve "bilgisayar" değişkenlerine göre $\mathrm{t}$ testi kullanılarak analiz edilmiştir. Verilerin analizinde, aşağıdaki tabloda yer alan değerlendirme aralığı kullanılmıştır (Tablo 2).

Tablo 2. Verilerin değerlendirme aralığ

\begin{tabular}{lll}
\hline Aralık & Seçenek & Aralığın Değeri \\
\hline $1.00-1.80$ & Hiç katılmıyorum & Çok zayıf \\
\hline $1.81-2.60$ & Katılmıyorum & Zayıf \\
\hline $2.61-3.40$ & Kararsızım & Orta \\
\hline $3.41-4.20$ & Katılıyorum & İyi \\
\hline $4.21-5.00$ & Kesinlikle katıllyorum & Çok iyi \\
\hline
\end{tabular}

\section{BULGULAR}

$\mathrm{Bu}$ araştırmada sınıf öğretmeni adaylarının ТPAB bilgilerini belirlemek ve bu alandaki bilgilerinin cinsiyet, kişisel bilgisayara ve internete sahip olup olmama değişkenlerine göre anlamlı bir şekilde değişip değişmediğini incelemek amaciyla, aritmetik ortalama ve standart sapma değerleri incelenmiştir. Elde edilen bulgular tablolar halinde sunulmuştur.

\subsection{Sınıf Öğretmeni Adaylarının Genel TPAB Düzeyine İlişkin Bulgular}

Araştırmanın "Sınıf öğretmeni adaylarının teknolojik pedagojik alan bilgileri nedir?" alt problemine ilişkin bulgular; TPAB'ın alt boyutlarında incelenmiş ve bu alt boyutlara ilişkin olarak, aritmetik ortalama ve standart sapma değerleri tablo halinde sunulmuş ve yorumlanmıştır (Tablo 3).

Tablo 3. Sınıf Öğretmen Adaylarının Teknolojik Pedagojik Alan Bilgisine (TPAB) İlişkin Ortalama ve Standart Sapma Değerleri

\begin{tabular}{|c|c|c|c|c|c|}
\hline Faktör & Alt Faktörler & $\mathbf{N}$ & $\overline{\mathrm{X}}$ & Ss & Ort. Karşılığı \\
\hline \multirow{8}{*}{ 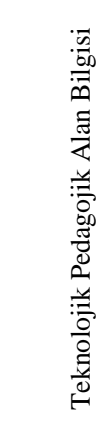 } & Teknoloji Bilgisi & \multirow{8}{*}{329} & 3,51 &, 72 & İyi düzey \\
\hline & Alan Bilgisi & & 3,39 &, 52 & Orta düzey \\
\hline & Pedagoji Bilgisi & & 3,78 & ,66 & İyi düzey \\
\hline & Pedagojik Alan Bilgisi & & 3,56 & ,67 & İyi düzey \\
\hline & Teknolojik Alan Bilgisi & & 3,68 &, 71 & İyi düzey \\
\hline & Teknolojik Pedagoji Bilgisi & & 3,78 &, 71 & İyi düzey \\
\hline & $\begin{array}{l}\text { Teknolojik Pedagojik Alan } \\
\text { Bilgisi }\end{array}$ & & 3,75 & ,68 & İyi düzey \\
\hline & TPABÖ Genel & & 3,59 &, 50 & İyi düzey \\
\hline
\end{tabular}


Tablo 3 'te verilen ortalama değerler incelendiğinde, araştırmaya katılan sınıf öğretmeni adaylarının TPAB'ın ortalama puanları "teknoloji bilgisi" alt boyutunda $\bar{X}$ $=3,51$, "alan bilgisi" alt boyutunda $\bar{X}=3,39$, "pedagoji bilgisi" alt boyutunda $\bar{X}=$ 3,78 , "pedagojik alan bilgisi" alt boyutunda $\bar{X}=3,56$, "teknolojik alan bilgisi" alt boyutunda $\bar{X}=3,68$, "teknolojik pedagoji bilgisi" alt boyutunda $\bar{X}=3,78$, "teknolojik pedagojik alan bilgisi" alt boyutunda $\bar{X}=3,75$ ve ölçeğin tamamında $\bar{X}=3,59$ olarak bulunmuştur. Bu değerler dikkate alındığında; sınıf öğretmeni adaylarının TPAB bilgi düzeyleri "alan bilgisi" boyutunda "orta düzey" diğer boyutlarda ise "iyi düzeyde" oldukları anlaşılmaktadır.

\subsection{Cinsiyet Değişkenine Göre Sınıf Öğretmeni Adaylarının TPAB'larına İlişkin Bulgular}

Araștırmanın "Sınıf öğretmeni adaylarının teknolojik pedagojik alan bilgileri cinsiyet değişkenine göre değişmekte midir?” alt problemine ilişkin bulgular; TPAB'ın alt boyutlarında incelenmiş ve bu alt boyutlara ilişkin olarak, aritmetik ortalama ve standart sapma değerleri tablo halinde sunulmuş ve yorumlanmıştır (Tablo 4).

Tablo 4. Sınıf Öğretmeni Adaylarının “Cinsiyet” Değişkenine Göre Teknolojik Pedagojik Alan Bilgisine İlişkin t-Testi Sonuçları

\begin{tabular}{|c|c|c|c|c|c|c|c|c|}
\hline & Alt Ölçek & Cinsiyet & $\mathbf{n}$ & $\overline{\mathrm{x}}$ & ss & sd & $\mathrm{t}$ & $\mathbf{p}$ \\
\hline \multirow{14}{*}{ 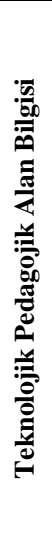 } & \multirow{2}{*}{ Teknoloji Bilgisi } & Kadın & 227 & 3,53 & ,68 & \multirow{2}{*}{327} & \multirow{2}{*}{,647 } & \multirow{2}{*}{, 518} \\
\hline & & Erkek & 102 & 3,47 &, 81 & & & \\
\hline & \multirow{2}{*}{ Alan Bilgisi } & Kadın & 227 & 3,38 &, 52 & \multirow{2}{*}{327} & \multirow{2}{*}{,- 653} & \multirow{2}{*}{, 514} \\
\hline & & Erkek & 102 & 3,42 &, 54 & & & \\
\hline & \multirow{2}{*}{ Pedagoji Bilgisi } & Kadın & 227 & 3,85 & ,65 & \multirow{2}{*}{327} & \multirow{2}{*}{3,018} & \multirow{2}{*}{, $003^{*}$} \\
\hline & & Erkek & 102 & 3,62 & ,66 & & & \\
\hline & \multirow{2}{*}{ Pedagojik Alan Bilgisi } & Kadın & 227 & 3,62 & ,69 & \multirow{2}{*}{327} & \multirow{2}{*}{2,576} & \multirow{2}{*}{, $010^{*}$} \\
\hline & & Erkek & 102 & 3,42 & ,59 & & & \\
\hline & \multirow{2}{*}{ Teknolojik Alan Bilgisi } & Kadın & 227 & 3,72 &, 71 & \multirow{2}{*}{327} & \multirow{2}{*}{1,728} & \multirow{2}{*}{,085 } \\
\hline & & Erkek & 102 & 3,58 &, 70 & & & \\
\hline & \multirow{2}{*}{$\begin{array}{l}\text { Teknolojik Pedagoji } \\
\text { Bilgisi }\end{array}$} & Kadın & 227 & 3,83 & ,71 & \multirow{2}{*}{327} & \multirow{2}{*}{2,063} & \multirow{2}{*}{, $040 *$} \\
\hline & & Erkek & 102 & 3,65 & 68 & & & \\
\hline & \multirow{2}{*}{$\begin{array}{l}\text { Teknolojik Pedagojik } \\
\text { Alan Bilgisi }\end{array}$} & Kadın & 229 & 3,80 & ,68 & \multirow{2}{*}{327} & \multirow{2}{*}{2,145} & \multirow{2}{*}{, $033^{*}$} \\
\hline & & Erkek & 104 & 3,62 & ,68 & & & \\
\hline
\end{tabular}

$\mathrm{P}<0.05$

Tablo 4'teki teknolojik pedagojik alan bilgi düzeylerinin cinsiyet değişkenine göre bağımsız gruplar $\mathrm{t}$ testi sonuçları incelendiğinde, aday öğretmenlerin TPAB'in pedagoji bilgisi $\left[\mathrm{t}_{(327)}=3,018 ; \mathrm{p}=0,003\right]$, pedagojik alan bilgisi $\left[\mathrm{t}_{(327)}=2,576 ; \mathrm{p}=0,010\right]$, teknoloji pedagoji bilgisi $\left[\mathrm{t}_{(327)}=2,063 ; \mathrm{p}=, 040\right]$ ve teknolojik pedagojik alan bilgisi $\left[\mathrm{t}_{(327)}=2,145 ; \mathrm{p}=, 033\right]$ boyutlarında cinsiyete göre kadın öğretmen adaylarının lehine anlamlı bir farklılık görülmektedir. TPAB'in teknoloji bilgi $\left[\mathrm{t}_{(331)}=, 647\right.$; $\mathrm{p}=, 518]$, alan bilgisi $\left[\mathrm{t}_{(327)}=-, 653 ; \mathrm{p}=, 514\right]$ ve teknolojik alan bilgisi $\left[\mathrm{t}_{(327)}=1,728\right.$; $\mathrm{p}=, 085]$, boyutlarında öğretmenlerin görüşleri arasında cinsiyete göre anlamlı bir 
farklılık görülmemektedir. Bu bulgulara göre, kadın öğretmen adayları, pedagoji bilgisi, pedagojik alan bilgisi, teknolojik pedagoji bilgisi ve teknolojik pedagojik alan bilgisi boyutlarında daha iyi düzeyde oldukları görülmüştür.

\subsection{Kişisel Bilgisayara Sahip Olma Değişkenine Göre Sınıf Öğretmeni Adaylarının TPAB'larına İlişkin Bulgular}

Araştırmanın "Sınıf öğretmeni adaylarının teknolojik pedagojik alan bilgileri kişisel bilgisayara sahip olma durumuna göre değişmekte midir?" alt problemine ilișkin bulgular; TPAB'ın alt boyutlarında incelenmiş ve bu alt boyutlara ilişkin olarak, aritmetik ortalama ve standart sapma değerleri tablo halinde sunulmuş ve yorumlanmıştır (Tablo 5).

Tablo 5. Aday Öğretmenlerin "Kişisel Bilgisayar” Değişkenine Göre Teknolojik Pedagojik Alan Bilgisine İlişkin t-Testi Sonuçları

\begin{tabular}{|c|c|c|c|c|c|c|c|c|}
\hline \multicolumn{2}{|c|}{ Alt Ölçek } & \multirow{2}{*}{$\begin{array}{l}\begin{array}{c}\text { Bilgisay } \\
\text { ar }\end{array} \\
\text { Var } \\
\text { Yok }\end{array}$} & \multirow{2}{*}{$\begin{array}{l}\frac{n}{286} \\
43\end{array}$} & \multirow{2}{*}{$\begin{array}{r}\bar{X} \\
3,58 \\
3,06\end{array}$} & \multirow{2}{*}{$\begin{array}{r}\text { ss } \\
, 70 \\
, 69\end{array}$} & \multirow{2}{*}{$\frac{\text { sd }}{327}$} & \multirow{2}{*}{$\frac{\mathbf{t}}{4,483}$} & \multirow{2}{*}{$\frac{\mathbf{p}}{, 000^{*}}$} \\
\hline \multirow{12}{*}{ 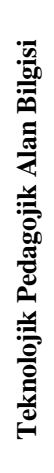 } & Teknoloji Bilgisi & & & & & & & \\
\hline & Alan Bilgisi & Var & 286 & 3,39 &, 51 & 327 & 279 & .781 \\
\hline & & $\begin{array}{l}\text { Yok } \\
\text { Var }\end{array}$ & $\begin{array}{l}43 \\
286\end{array}$ & $\begin{array}{l}3,37 \\
3,81\end{array}$ & ,61 & & & \\
\hline & Pedagoji Bilgisi & Yok & 43 & 3,61 & 65 & 327 & 1,807 & ,072 \\
\hline & Pedagojik Alan & Var & 286 & 3,60 & 65 & 327 & 2840 & 005 \\
\hline & Bilgisi & Yok & 43 & 3,29 &, 74 & 321 & 2,840 & , 005 \\
\hline & Teknolojik Alan & Var & 286 & 3,70 & ,72 & 327 & 1566 & 118 \\
\hline & Bilgisi & Yok & 43 & 3,52 & ,65 & 521 & 1,500 & , 110 \\
\hline & Teknolojik Pedagoji & Var & 286 & 3,81 & ,71 & 327 & 103 & $036 *$ \\
\hline & Bilgisi & Yok & 43 & 3,56 & ,60 & 521 & 2,100 & . \\
\hline & Teknolojik & Var & 286 & 3,80 & ,66 & & & \\
\hline & $\begin{array}{l}\text { Pedagojik Alan } \\
\text { Bilgisi }\end{array}$ & Yok & 43 & 3,37 &, 70 & 327 & 3,952 &, $000^{*}$ \\
\hline
\end{tabular}

Tablo 5'de teknolojik pedagojik alan bilgi düzeylerinin bir bilgisayara sahip olma değişkenine göre bağımsız gruplar $\mathrm{t}$ testi sonuçları incelendiğinde, aday öğretmenlerin TPAB'ın teknoloji bilgisi $\left[\mathrm{t}_{(327)}=4,483 ; \mathrm{p}=0,000\right]$, pedagojik alan bilgisi $\left[\mathrm{t}_{(327)}=2,840 ; \mathrm{p}=0,005\right]$, teknolojik pedagoji bilgisi $\left[\mathrm{t}_{(327)}=2,103 ; \mathrm{p}=0,036\right]$ ve teknolojik pedagojik alan bilgisi $\left[\mathrm{t}_{(327)}=3,952 ; \mathrm{p}=, 005\right]$ boyutlarında bir bilgisayara sahip olma durumuna göre bilgisayarı olan öğretmen adaylarının lehine anlamlı bir farklılık görülmektedir. TPAB'ın alan bilgisi $\left[\mathrm{t}_{(331)}=, 279 ; \mathrm{p}=, 781\right]$, pedagoji bilgisi $\left[\mathrm{t}_{(331)}=1,807 ; \mathrm{p}=, 072\right.$ ve teknolojik alan bilgisi $\left[\mathrm{t}_{(327)}=1,566 ; \mathrm{p}=, 118\right]$ boyutlarında öğretmenlerin görüşleri arasında bilgisayar değişkenine göre anlamlı bir farklılık görülmemektedir. Bu bulgulara göre, bir bilgisayara sahip olan öğretmen adayları, teknoloji bilgisi, pedagojik alan bilgisi, teknoloji pedagoji bilgisi ve teknolojik pedagojik alan bilgisi boyutlarında daha iyi düzeyde oldukları görülmüştür.

\subsection{Kişisel İnternete Sahip Olma Değişkenine Göre Sınıf Öğretmeni Adaylarının TPAB'larına İlişkin Bulgular}

Araştırmanın "Sınıf öğretmeni adaylarının teknolojik pedagojik alan bilgileri kişisel internete sahip olma durumuna göre değişmekte midir?” alt problemine ilişkin 
bulgular; TPAB'ın alt boyutlarında incelenmiş ve bu alt boyutlara ilişkin olarak, aritmetik ortalama ve standart sapma değerleri tablo halinde sunulmuş ve yorumlanmıştır (Tablo 6).

Tablo 6. Aday Öğretmenlerin "Kişisel İnternet” Değiş̧kenine Göre Teknolojik Pedagojik Alan Bilgisine İlişkin t-Testi Sonuçları

\begin{tabular}{|c|c|c|c|c|c|c|c|c|}
\hline \multicolumn{2}{|c|}{ Alt Ölçek } & İnternet & $\mathbf{n}$ & $\bar{x}$ & ss & Sd & $\mathbf{t}$ & p \\
\hline \multirow{14}{*}{ 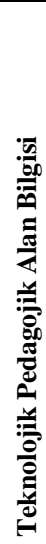 } & \multirow{2}{*}{ Teknoloji Bilgisi } & Var & 264 & 3,60 & ,69 & \multirow{2}{*}{327} & \multirow{2}{*}{4,601} & \multirow{2}{*}{, $000 *$} \\
\hline & & Yok & 65 & 3,15 & ,73 & & & \\
\hline & \multirow{2}{*}{ Alan Bilgisi } & Var & 264 & 3,39 &, 53 & \multirow{2}{*}{327} & \multirow{2}{*}{, 144} & \multirow{2}{*}{,885 } \\
\hline & & Yok & 65 & 3,38 &, 52 & & & \\
\hline & \multirow{2}{*}{ Pedagoji Bilgisi } & Var & 264 & 3,83 & ,65 & \multirow{2}{*}{327} & \multirow{2}{*}{2,707} & \multirow{2}{*}{,007* } \\
\hline & & Yok & 65 & 3,58 & ,68 & & & \\
\hline & \multirow{2}{*}{ Pedagojik Alan Bilgisi } & Var & 264 & 3,60 & ,68 & \multirow{2}{*}{327} & \multirow{2}{*}{2,436} & \multirow{2}{*}{, $015^{\prime}$} \\
\hline & & Yok & 65 & 3,38 &, 59 & & & \\
\hline & \multirow{2}{*}{ Teknolojik Alan Bilgisi } & Var & 264 & 3,73 &, 70 & \multirow{2}{*}{327} & \multirow{2}{*}{2,505} & \multirow{2}{*}{, $013^{*}$} \\
\hline & & Yok & 65 & 3,48 & ,73 & & & \\
\hline & Teknolojik Pedagoji & Var & 264 & 3,80 &, 73 & \multirow{2}{*}{327} & \multirow{2}{*}{1,488} & \multirow{2}{*}{,080 } \\
\hline & Bilgisi & Yok & 65 & 3,66 &, 58 & & & \\
\hline & \multirow{2}{*}{$\begin{array}{l}\text { Teknolojik Pedagojik } \\
\text { Alan Bilgisi }\end{array}$} & Var & 264 & 3,80 & 66 & \multirow{2}{*}{327} & \multirow{2}{*}{2,803} & \multirow{2}{*}{, $005^{*}$} \\
\hline & & Yok & 65 & 3,53 & ,74 & & & \\
\hline
\end{tabular}

Tablo 6'daki teknolojik pedagojik alan bilgi düzeylerinin internete sahip olma değişkenine göre bağımsız gruplar $t$ testi sonuçları incelendiğinde, aday öğretmenlerin TPAB'ın teknoloji bilgisi $\left[\mathrm{t}_{(327)}=4,601 ; \mathrm{p}=0,000\right]$, pedagojik bilgisi $\left[\mathrm{t}_{(327)}=2,707 ; \mathrm{p}=0,007\right]$, pedagojik alan bilgisi $\left[\mathrm{t}_{(327)}=2,436 ; \mathrm{p}=0,015\right]$, teknolojik alan bilgisi $\left[\mathrm{t}_{(327)}=2,505 ; \mathrm{p}=0,013\right]$ ve teknolojik pedagojik alan bilgisi $\left[\mathrm{t}_{(327)}=2,803\right.$; $\mathrm{p}=, 005]$ boyutlarında internete sahip olma durumuna göre interneti olan öğretmen adaylarının lehine anlamlı bir farklılık görülmektedir. TPAB'ın alan bilgisi $\left[\mathrm{t}_{(331)}=\right.$ $, 144 ; \mathrm{p}=, 885]$ ve teknolojik pedagoji bilgisi $\left[\mathrm{t}_{(327)}=1,488 ; \mathrm{p}=, 080\right]$ boyutlarında öğretmenlerin görüşleri arasında internet değişkenine göre anlamlı bir farklılık görülmemektedir. Bu bulgulara göre, internete sahip olan öğretmen adayları, teknoloji bilgisi, pedagoji bilgisi, pedagojik alan bilgisi, teknolojik alan bilgisi ve teknolojik pedagojik alan bilgisi boyutlarında daha iyi düzeyde oldukları görülmüştür.

\section{TARTIŞMA, SONUÇ ve ÖNERİLER}

$\mathrm{Bu}$ araştırmada bir fakültede öğrenim gören ve mezun olmak üzere olan sınıf öğretmeni adaylarının Teknolojik Pedagojik Alan Bilgisi (TPAB) düzeyleri cinsiyet, kişisel bilgisayara sahip olma ve kişisel internet erişimine sahip olma değişkenleri açısından incelenmiştir. Araştırmada ulaşılan bulgulardan ilkine göre ölçeğin tamamından aldıkları puanlara bakıldığında katılımcı sınıf öğretmeni adaylarının, genel TPAB düzeylerinin "alan bilgisi" orta düzeyde olmak üzere diğer tüm boyutlarda "iyi” düzeyde olduğu tespit edilmiştir. Bu sonuç Gündoğmuş (2013) ve Altun ve Akyıldız (2017)'ın sadece sınıf öğretmeni adayları değil diğer branşlardaki öğretmen adaylarının da bulunduğu tarama çalışmaları bulgularıyla paralellik 
göstermektedir. Sözü geçen çalışmalarda da öğretmen adaylarının genel TPAB düzeylerinin iyi düzeyde olduğu sonucuna ulaşılmıştır. Günümüzde üniversite düzeyinde öğrenim gören öğrencilerin mobil teknolojiler sayesinde internete erişimlerinin oldukça kolay olması, eğitim fakültesindeki derslerde bu teknolojilerden yararlanarak bireysel ve grup çalışmaları yapmaları onların hem teknolojik hem de pedagojik bilgilerinin artmasına etki eden önemli bir faktör olarak görülebilir. Ayrıca araştırmaya katılan öğretmen adaylarının son sınıfta öğretmenlik uygulamaları için okullarda pratik yapıyor olmaları ve uygulama yaptıkları sınıflarda bulunan akıllı tahta gibi teknolojilerden yararlanıyor olmaları da öğretmen adaylarının TPAB düzeylerinin gelişmesine katkı yaptığı söylenebilir. Buna karşılık Pamuk (2012), çalışmasında öğretmen adaylarının teknolojik beceri açısından oldukça yeterli düzeyde olduklarını ancak öğretim deneyimlerinin sınırlı olması nedeniyle pedagojik bilgilerinin istenen düzeyde olmadığını tespit etmiştir.

Cinsiyet değişkeni ile katılımcıların TPAB düzeyleri arasındaki ilişkiyi inceleyen çok fazla çalışma bulunmaktadır. Bu çalışmaların bazılarında cinsiyet ile katılımcıların TPAB arasında çoğu zaman anlamlı ilişkiler bulunamazken (Çoklar, 2014; Ersoy, Yurdakul ve Ceylan, 2016; Karaca, 2015; Karakaya ve Yazıc1, 2017; Öztürk, 2013), bu çalışmada olduğu gibi bazı çalışmalarda ise cinsiyet ile TPAB boyutları arasında anlamlı ilişkilerin olduğu tespit edilmiştir (Altun, 2013; Altun ve Akyıldız, 2017; Öz, 2015). Bu çalışmada TPAB ölçeğinin pedagoji bilgisi, pedagojik alan bilgisi, teknolojik pedagoji bilgisi ve teknolojik pedagojik alan bilgisi boyutlarında kadın sınıf öğretmeni adaylarının erkek öğretmen adaylarına göre daha iyi puanlar elde ettikleri tespit edilmiştir. Kadın öğretmen adaylarının puanlarının erkek öğretmen adaylarına göre yüksek çıkmasını etkileyen ölçülmesi zor birçok etken mevcut olabilir. Erkek katılımcıların teknolojiye daha çok kadın öğretmen adaylarının ise sınıf içi öğretim yönetme ve tekniklerine yatkın olmaları bu etkenlerden biri olarak gösterilebilir. Ancak bu tür hipotezlerin daha derinlemesine incelenmesi gerekmektedir.

Araştırmada odaklanılan konulardan biri de sınıf öğretmeni adaylarının bilgisayara ve internet erişimine sahip olma durumu ile TPAB düzeyleri arasındaki ilişkinin incelenmesidir. Elde edilen sonuçlar incelendiğinde bilgisayara sahip olma değişkeninin ölçeğin bazı alt boyutlarında etkili bir değişken olduğunu göstermektedir. Bilgisayara sahip olan sınıf öğretmeni adayları ile bilgisayara sahip olmayan adaylar arasında genel TPAB ölçeğinin teknoloji bilgisi (TB), pedagojik alan bilgisi (PAB), teknoloji pedagoji bilgisi (TPB) ve teknolojik pedagojik alan bilgisi (TPAB) boyutlarında bilgisayar ve internet erişimi olanların lehine anlamlı farklılıklar olduğu tespit edilmiştir. Bu bulgu Inan ve Lowther (2010), Altun (2013) ve Altun ve Akyıldız (2017)'un çalışmalarında elde ettikleri bulgularla örtüşmektedir. Teknolojik kaynaklara erişim ile öğretmenlerin bilgisayar kullanma yeterlikleri arasında pozitif bir ilişki olduğunu tespit eden Inan ve Lowther (2010), diğer demografik değişkenlerle birlikte bilgisayara erişimin öğretmenler açısında eğitime teknoloji entegrasyonu sürecinde etkili faktörlerden bir olduğunu belirtmişlerdir.

Benzer şekilde bilgi ve iletişim çağını yaşadığımız günümüzde özellikle internete erişim genç bireyler için yaşamın vazgeçilmez bir parçası haline gelmiştir. $\mathrm{Bu}$ araştırmaya katılan örneklemdeki sınıf öğretmeni adaylarının \%80'inin internet erişimine (büyük olasılıkla mobil araçlar aracılığıyla) sahip oldukları görülmektedir. 
$\mathrm{Bu}$ çalışmada İnternete erişim değişkeni ile TPAB ölçeğinin bazı boyutlarında internete sahip olan öğretmen adaylarının lehine anlamlı farklılıklar bulunmuştur. Diğer bir deyişle her an internete erişim sağlayan sınıf öğretmeni adayları ile internet erişimi olan veya olmayan öğretmen adayları arasında teknoloji bilgisi (TB), pedagoji bilgisi (PB), pedagojik alan bilgisi (PAB), teknolojik alan bilgisi (TAB) ve teknolojik pedagojik alan bilgisi (TPAB) boyutlarında anlamlı farklılıklar mevcuttur. İnternet erişimine sahip olan sınıf öğretmeni adaylarının ölçeğin bu alt boyutlarında daha iyi bilgi düzeyinde oldukları sonucuna ulaşılmaktadır. Altun ve Akyıldız (2017) diğer branş öğretmenlerinin de bulunduğu çalışmalarında internet değişkeninin öğretmen adaylarının genel TPAB düzeyleri için farklılık yaratan bir değişken olmadığı yönünde bulguya erişirken, bu çalışmada ise internet erişimi değişkenin öğretmen adaylarının TPAB düzeylerini yordamada önemli bir değişken olduğu ortaya konmuştur. Bu bulgu daha önce Altun (2013) tarafından sınıf öğretmenleri ile yapılan çalışma bulguları ile paralellik göstermektedir. Sınıf öğretmenliği alanı disiplinler arası bir yaklaşıma dayalı olmasından dolayı, öğretmen adaylarının fakülte eğitimleri boyunca farklı alanlardaki bilgilere erişim ihtiyacı beklide diğer branşlara göre daha fazla gereksinim duydukları bir ihtiyaç olduğundan, internet araştırmalarına sıklıkla başvurmalarını gerektirmektedir. Özellikle sınıf öğretmenliği programında farklı disiplin alanlarındaki derslerin (Fen Bilgisi, Matematik, Sosyal Bilgiler, Hayat Bilgisi, Türkçe, Resim, Müzik Beden Eğitimi gibi) yer alması ve derslerde bunlara yönelik sunumların hazırlanıp uygulanması öğretmen adaylarının İnternette araştırma yapma (materyal bulma, bilgi ve belgelere erişim gibi) eğilim ve ihtiyaçlarını artırmaktadır. Bu nedenle internete erişim değişkeni bu öğretmen adaylarının teknolojiyi öğretme ve öğrenme faaliyetlerine entegre etme süreçlerinde önemli bir rol oynayan faktör olarak karşımıza çıkmaktadır.

$\mathrm{Bu}$ sonuçlardan yola çıkılarak yapılan bu araştırmada genel olarak sınıf öğretmeni adaylarının Teknolojik Pedagojik Alan Bilgilerinin iyi düzeyde olduğu sonucuna ulaşılmıştır. İleriki çalışmalarda bu sınıf öğretmeni adaylarının bu bilgi düzeylerini sınıf ortamlarına ne derece yansıtabildiklerine yönelik gözlem bulguları da içeren deneysel veya tarama çalışmaları yapılabilir.

Teknolojinin sunduğu firsatlardan tüm öğretmen adaylarının, öğretmenlerin ve öğrencilerin etkin bir şekilde yararlanabilmeleri için okul ve eğitim fakültesi programlarına TPAB modelinin entegre edilmesi önerilmektedir (Kaya ve Dağ, 2013). Bu modelin eğitim fakültelerine etkin bir şekilde uyarlanabilmesi için öncelikle fakültelerde bilgisayar, internet erişimi, yazılım gibi altyapı sorunlarının çözümlenmesi gerekmektedir. Buna ek ve önemli olarak teknolojinin pedagojiye etkin bir şekilde hizmet edebilmesi için TPAB modelinin veya benzer modellerin geliştirilerek sınıf öğretmenliği lisans müfredatlarına entegrasyonu sağlanmalıdır. Günümüzde bir sınıf öğretmeni adayının ilkokul programındaki kazanımı okuyup anlayarak, bu kazanıma uygun hangi yöntemi ve hangi teknolojik aracı kullanacağına karar vererek bir öğretim tasarımı yapabilmesi beklenmektedir. Bu tasarımı yapabilen bir sınıf öğretmeni bu anlamda elindeki müfredatı doğru bir şekilde anlayacak ve sınıfında öğrencileri için zengin öğrenme etkinlikleri ve ortamlarını hazırlama becerisine sahip olacaktır. Z kuşağı olarak adlandırılan günümüz çocuklarının dijital öğrenme ihtiyaçlarının karşılanabilmesi için bu sınıflarda öğretim yapacak olan öğretmen adaylarının da 21. yüzyıl becerileri dikkate alınarak eğitilmesi gerekmektedir. 


\section{KAYNAKLAR}

Altun, T. (2007). Information and communications technology (ICT) in initial teacher education: What can Turkey learn from range of international perspectives?. Journal of Turkish Science Education, 4(2), 44.

Altun, T. (2013).Examination of classroom teachers' technological, pedagogical and content knowledge (TPACK) on the basis of their demographic profiles, Croatian Journal of Education, 15 (2), 365-397.

Altun, T. veAkyıldız, S. (2017). Investigating student teachers' technological Pedagogical Content Knowledge (TPACK) levels based on some variables, European Journal of Education Studies, 3 (5), 467-485.

Atay, D. (2003). Öğretmen Ĕ̆itimi ve Öğretimde Yaklaşımlar. Ankara: Nobel Yayın Dağıtım.

Bilgin, İ., Tatar, E., ve Ay, Y. (2012). Sınıf Öğretmeni Adaylarının Teknolojiye Karşı Tutumlarının Teknolojik Pedagojik Alan Bilgisi (TPAB)'ne Katkısının İncelenmesi. X. Ulusal Fen Bilimleri ve Matematik Ĕgitimi Kongresi Bildiriler Kitabl, 125. http://kongre.nigde.edu.tr (Erişim Tarihi: 12.01.2016).

Bozkurt, A., ve Cilavdaroğlu, A. K. (2011). Matematik ve sınıf öğretmenlerinin teknolojiyi kullanma ve derslerine teknolojiyi entegre etme algılar1. Kastamonu Ĕ̈itim Dergisi, 19(3), 859-870.

Çoklar, A. N. (2014). Sınıf Öğretmenliği Öğretmen Adaylarının Teknolojik Pedagojik İçerik Bilgisi Yeterliklerinin Cinsiyet ve BİT Kullanım Aşamaları Bağlamında İncelenmesi. Eğitim ve Bilim, 39 (175), 319-330.

Çoklar, A. N., Kılıçer, K., ve Odabaşı, H. F. (2007). Eğitimde teknoloji kullanımına eleştirel bir bakış: teknopedagoji. in 7nd International Educational Technology Conference (p. 3-5).

Ekiz, D. (2006). Öğretmen Eğitimi ve Öğretimde Yaklaşımlar. Nobel Kitabevi: Ankara.

Gönen, S., ve Kocakaya, (2015). Pedagojik formasyon programına katılan öğrencilerinin teknopedagojik eğitim yeterliklerinin çeşitli değişkenlere göre incelenmesi. Ĕ̆itim ve Öğretim Araştırmaları Dergisi, 4 (4), 82-90.

Gündoğmuş, N. (2013). Öğretmen adaylarının teknolojik pedagojik alan bilgileri ile öğrenme stratejileri arasındaki ilişkinin incelenmesi. Yayımlanmamış Yüksek Lisans Tezi, Necmettin Erbakan Üniversitesi, Konya.

Inan, F. A., \& Lowther, D. L. (2010). Factors affecting technology integration in K12 classrooms: A path model. Educational Technology Research and Development, 58(2), 137-154.

Karadeniz, Ş., ve Vatanartıran, S. (2015). SınıfÖğretmenlerinin Teknolojik Pedagojik Alan Bilgilerinin İncelenmesi. İlkögretim Online, 14(3), 1017-1028.

Karakuyu, A. (2015), Bazı Değişkenlerin İlköğretim Sınıf Öğretmenlerinin Teknolojik Pedagojik Alan Bilgilerine Katkılarının İncelenmesi, Yayımlanmamış Yüksek Lisans Tezi, Mustafa Kemal Üniversitesi, Sosyal Bilimler Enstitüsü, Hatay. 
Kaya, S., ve Dağ, F. (2013). Turkish Adaptation of Technological Pedagogical Content Knowledge Survey for Elementary Teachers. Educational Sciences: Theory and Practice, 13(1), 302-306.

Koehler, M. J., \& Mishra, P. (2009). What is technological pedagogical content knowledge? .Contemporary Issues in Technology and Teacher Education, 9 (1), 60-70.

Koehler, M. J. \& Mishra P. (2005). What happens when teachers design educational technology? The development of technological pedagogical content knowledge. J. Educational Computing Research, 32(2), 131-152.

Koehler, M. J. \& Mishra, P. (2008).Introducing TPCK in AACTE committee on innovation and technology: The handbook of technological pedagogical content knowledge (TPCK) for educators. New York: American Association of Colleges of Teacher Education and Routledge.

Kula, A. (2015). Öğretmen Adaylarının Teknolojik Pedagojik Alan Bilgisi (TPAB) Yeterliliklerinin İncelenmesi: Bartın Üniversitesi Örneği. Akademik Sosyal Araştırmalar Dergisi, 3(12), 395-412.

Kuşkaya-Mumcu, F., Haşlaman, T. ve Usluel, Y.K. (2008). Teknolojik Pedagojik İçerik Bilgisi Modeli Çerçevesinde Etkili Teknoloji Entegrasyonunun Göstergeleri. International EducationalTechnology Conference, Eskişehir, Anadolu Üniversitesi.

Mishra, P. \& Koehler, M. (2005). "Educational technology by design: Results from a survey assessing its effectiveness." Society for Information Technology \& Teacher Education International Conference, Volume 2005/1, s. 1511-1517.

Öksüz, C., Şerife, A. K., ve Sanem, U. Ç. A. (2009). İlköğretim matematik öğretiminde teknoloji kullanımına ilişkin algı ölçeği. Yüzüncü Yll Üniversitesi Eğitim Fakültesi Dergisi, 6(1), 1-19.

Öztürk, E. (2013). Sınıf Öğretmeni Adaylarının Teknolojik Pedagojik Alan Bilgilerinin Bazı Değişkenler Açısından Değerlendirilmesi. Uşak Üniversitesi Sosyal Bilimler Dergisi, 6(2), 223-228.

Pamuk, S. (2012). Understanding pre-service teachers' technology use through TPACK framework. Journal of Computer Assisted Learning, 28(5), 425-439.

Sancar-Tokmak, H., Yavuz Konakman, G., ve Yanpar Yelken, T. (2013). Mersin Üniversitesi Okul Öncesi Öğretmen Adaylarının Teknolojik Pedagojik Alan Bilgisi (TPAB) Özgüven Algılarının İncelenmesi, Ahi Evran Üniversitesi Kırşehir Eğitim Fakültesi Dergisi (KEFAD), 14(1), 35-51.

Schmidt, D., Baran, E., Thompson A., Koehler, M. J., Mishra, P. \& Shin, T. (2009). Technological Pedagogical Content Knowledge (TPACK): The Development and Validation of an Assessment Instrument for Pre-service Teachers. Journal of Research on Technology in Education, 42(2), 123-149.

Shulman, L. S. (1986). Those who understand; Knowledge growth in teaching. Educational Researcher, 15(2), 4-14. 
Şimşek, Ö., Demir, S., Bağçeci, B., ve Kinay, İ. (2013). Öğretim elemanlarının teknopedagojik eğitim yeterliliklerinin çeşitli değişkenler açısından incelenmesi. Ege Eğitim Dergisi, 14(1), 1-23.

TED. (2009). Öğretmen Yeterlikleri Özet Rapor. “Öğretmene Yatırım, Geleceğe Atılım" Ankara: Türk Eğitim Derneği.

Usluel, Y. K., Özmen, B., \& Çelen, F. K. (2015). BíT'in Öğrenme Öğretme Sürecine Entegrasyonu ve Teknolojik Pedagojik Alan Bilgisi Modeline Eleştirel Bir Bakış. Eğitim Teknolojisi Kuram ve Uygulama, 5(1), 34-54.

Yılmaz, G. K. (2015). Türkiye'deki Teknolojik Pedagojik Alan Bilgisi Çalışmalarının Analizi: Bir Meta-Sentez Çalışması. Eğitim ve Bilim, Cilt 40. Sayı. 178 103122

Yurdakul, I. K. (2011). Öğretmen adaylarının teknopedagojik eğitim yeterliklerinin bilgi ve iletişim teknolojilerini kullanımları açısından incelenmesi. Hacettepe Üniversitesi Eğitim Fakültesi Dergisi, 40(40), 397-408. 


\section{EXTENDED ABSTRACT}

\section{Introduction}

Today a transformation from behaviorist approach to "technological pedagogical content knowledge" approach can be seen in teaching profession which integrates content knowledge, pedagogy, and technology (TED, 2009). This means that teachers are now required to integrate technology into teaching-learning processes effectively. In order to achieve this aim teacher need to possess knowledge of technology, pedagogy and the content (Koehler and Mishra, 2005; 2008).

Technological Pedagogical Content Knowledge (TPACK) model was established on Shulman's (1986) concept of pedagogical content knowledge. The technology component of the model consist of tools such as the computer, the internet, video, Blackboard, textbooks; pedagogy component of the model includes teaching and learning methods, strategies and processes; and the content component of the model involves subject matter knowledge (Kuşkaya Mumcu et al., 2008:397). In today's contemporary world it is not possible to put curriculum into practice without utilizing information and communication technologies effectively. In order to increase the effectiveness of technology usage in teaching and learning processes, there are some efforts in education faculties which explore the possibilities of technology integration into general culture and pedagogy courses. These studies were named as "techno-pedagogy" in Turkey (Çoklar, Kılıçer, and Odabaş1, 2007; Öksüz, Ak and Uça, 2009; Yurdakul, 2011; Şimşek, Demir, Bağçeci and Kinay, 2013; Gönen and Kocakaya, 2015). It is expressed that despite technology courses are available in teacher education programs, teacher candidates have the lack of skills and knowledge in integrating instructional technologies into the processes of teaching and measurement and assessment adequately (Çoklar, Kılıçer, and Odabaşı, 2007; Altun, 2007; Bilgin, Tatar and Ay, 2012).

Research on TPACK has increased in recent years dramatically however, limited studies carried out on primary teacher candidates' TPACK levels compare to other fields of teacher education.

In this context, this study aims to investigate Technological Pedagogical Content Knowledge (TPACK) levels of primary pre-service teachers based on some variables (such as gender, having personal computer and internet connection). In the study answers sought to the following research questions:

1. What is the TPACK level of pre-service primary teachers' in general?

2. Is there any meaningful difference between pre-service primary teachers' TPACK and gender variable?

3. Is there any meaningful difference between pre-service primary teachers' TPACK and having a personal computer variable?

4. Is there any meaningful difference between pre-service primary teachers' TPACK and internet access variable?

\section{Method}

In this study, survey method was utilized in order to obtain required data. 329 primary pre-service students who attend to Karadeniz Technical University, Primary Teacher Education Programme, were included in the study. In order to collect data Survey of Pre-service Teachers' Knowledge of Teaching and Technology which was originally developed by Schmidt et al., (2009) and adapted into Turkish by Bahçekapili, (2011) was used as the data collection instrument. Data were analyzed by SPPS 18.0 software and ANOVA, independent t-tests were employed during data analysis processes.

\section{Findings}


First of all, findings of the study show that primary teacher candidates have "good" level of TPACK in general. General mean scores of TPACK scale was found as $=3,59$ which means that participants technological pedagogical content knowledge level are well above the average.

In regard to gender variable, meaningful differences were found in some dimensions of TPACK scale in favor of female participants. Results show that female teacher candidates have better scores than male counterparts in pedagogy knowledge, pedagogical content knowledge, technological pedagogical knowledge and technological pedagogical knowledge dimensions of whole TPACK scale.

According to findings having a personal computer is another variable which influences primary pre-service teachers TPACK. Results illustrate that teacher candidates, who own a personal computer have better scores in technology knowledge, pedagogical content knowledge and technological pedagogical content knowledge dimensions of TPACK scale than teacher candidates who does not have a personal computer.

Finally, having an internet connection is also another influential variable on teacher candidates TPACK level. Similar to the previous variable, participants who have the internet connection available have better scores than participants who have no internet connection in certain dimensions (technology knowledge, pedagogical knowledge, pedagogical content knowledge, technological content knowledge and technological pedagogical content knowledge) of TPACK scale.

\section{Discussion and Conclusion}

One of the results of the study shows that general TPACK level of primary pre-service teachers is at the good level. This result is parallel with previous studies carried out Gündoğmuş (2013) and Altun and Akyıldız (2017) who also found out that pre-service teachers have a good level of TPACK. Due to the availability of mobile technologies today, internet access is very easy for university students and this helps students to develop skills in searching information on the net for in-class teaching and learning activities. Hence, it can be said that today student teachers have opportunities to integrate technology into teaching and learning processes especially during their Teaching Practices in schools which directly helps them to develop both technological and pedagogical skills together which improves their TPACK level.

The influence of gender variable on TPACK was investigated in many studies earlier (Öztürk, 2013; Çoklar, 2014; Karaca, 2015; Ersoy, Yurdakul and Ceylan, 2016; Karakaya and Yazıc1, 2017) and different results were found. In this study female students scored better points than male counterparts in certain dimensions of TPACK and this result is supported bother studies carried out by Altun, 2013; Öz, 2015; Altun and Akyıldız, 2017).

Investigating relationships between having a computer and internet connection variables and pre-service primary teachers' TPACK level was another dimension of the study. Results indicate that both variables influence participants' general TPACK level, particularly in some sub-dimensions. Similar results were found in the studies carried out by Inan and Lowther (2010), Altun (2013) and Altun and Akyıldız (2017).

In light of these results, it can be said that general TPACK level of primary pre-service teachers is good. In the future, experimental studies based on classroom observations can be carried out in order to investigate whether this good level of knowledge is mirrored to real classroom environments by those teachers.

It is suggested that in order for students and teacher to benefit from the opportunities presented by technology effectively, TPACK model needs to be integrated to both education faculty and school curricula (Kaya and Dağ, 2013). First of all infrastructure issues needs to be considered and then student teachers should be educated on reading curriculum and deciding on how to choose appropriate teaching methods with suitable technology in order to design instruction for classroom teaching-learning activities. 